CLINICAL STUDY

\title{
The cytologic category of oncocytic (Hurthle) cell neoplasm mostly includes low-risk lesions at histology: an institutional experience
}

\author{
Esther Diana Rossi ${ }^{1}$, Maurizio Martini ${ }^{1}$, Patrizia Straccia ${ }^{1}$, Marco Raffaelli $^{2}$, Ilaria Pennacchia ${ }^{1}$, \\ Eleonora Marrucci ${ }^{1}$, Celestino Pio Lombardi ${ }^{2}$, Alfredo Pontecorvi ${ }^{3}$ and Guido Fadda ${ }^{1}$ \\ ${ }^{1}$ Division of Anatomic Pathology and Histology, ${ }^{2}$ Division of Endocrine Surgery and ${ }^{3}$ Division of Endocrinology, Agostino Gemelli' School of Medicine, \\ Università Cattolica del Sacro Cuore, Largo Francesco Vito, 1, 00168 Rome, Italy
}

(Correspondence should be addressed to E D Rossi; Email: esther.rossi@rm.unicatt.it)

\begin{abstract}
Design: The cytological diagnosis of oncocytic/Hurthle cell neoplasms (OCN) represents a challenge with which cytopathologists face up to in their practice. The majority of these lesions undergo surgery for a definitive characterization of the nature mainly due to their more aggressive behavior than other malignant follicular lesions. In this study, we aimed at the evaluation of the effective malignant rate in a large cohort of OCNs.

Methods: From January 2008 to December 2011, we analyzed 150 cyto-histological OCNs and 64 benign oncocytic/Hurthle lesions (BOL). Both groups of patients were analyzed for clinical and cytohistological parameters. All the nodules were sampled under sonographic guidance and processed with the liquid-based cytological method.

Results: In agreement with literature, we found a significant correlation only with female gender in both OCN $(P=0.0160)$ and BOL groups. The 64 BOLs were histologically diagnosed as 15 Hashimoto thyroiditis (HT), 45 hyperplastic nodules in HT, and four papillary thyroid carcinomas (PTC, 6.2\%). The 150 OCNs resulted in $141(94 \%)$ oncocytic adenomas and nine $(6 \%)$ malignant lesions. The latter group included five oncocytic carcinomas (OCC), three oncocytic variants of PTC, and one macrofollicular PTC featured by mild nuclear clearing with a dispersive cellular pattern. The malignant rate was respectively $6.2 \%$ in BOLs without any OCC whereas $3.3 \%$ OCC diagnosed in the OCN category.

Conclusions: Our OCNs mostly resulted in histological adenomas with a lower rate of malignancy than in other series. Some morphological parameters (nuclear clearing, dysplasia, and dispersive cellular pattern) might be helpful in stratifying OCN patients into different risks of malignancy.
\end{abstract}

European Journal of Endocrinology 169 649-655

\section{Introduction}

Fine needle aspiration cytology (FNAC) is worldwide regarded as the first approach for the evaluation of thyroid nodules. It is a simple, safe, and cost-effective method achieving a correct definition of the nature of the lesions in more than $70 \%$ of cases (1).

Even though with all these advantages, FNAC implies two important drawbacks assessed in: i) the unpredictable rate of inadequate diagnoses and ii) a nonnegligible rate of indeterminate diagnoses which may represent up to $25 \%$ of all thyroid lesions. This latter category, defined as 'the grey zone' by LiVolsi \& Baloch (2), encompasses both benign lesions, including the problematic oncocytic/Hurthle cell proliferations and malignant histological entities.

The category of oncocytic/Hurthle cell neoplasm (OCN) embraces not only a wide range of histological diseases including oncocytic/Hurthle cell adenoma (OCA), oncocytic/Hurthle cell carcinoma (OCC) but also nonneoplastic lesions such as hyperplastic cell nodules (HNN) in Hashimoto thyroiditis (HT) and nodular goiter with oncocytic/Hurthle cell metaplasia $(3,4,5,6)$.

The recognition of oncocytic cell neoplasm represents an important and painstaking task for cytopathologists mainly underlined by the high risk of malignancy (ranging from 20 to $45 \%$ ) reported in different series $(7,8,9,10)$. A further emphasis has been added by the reporting of more aggressive behavior and outcome of these tumors compared with the 'follicular' nononcocytic counterpart $(9,10,11)$. These data are surprising mainly because the true OCN category represents only $3-5 \%$ of all thyroid neoplasm and OCC accounts for only $2-3 \%$ of all thyroid cancers $(8,9)$.

Many papers have reckoned that thyroid FNAC is very accurate and helpful in identifying the 
oncocytic/Hurthle cell morphology. Nonetheless, the definitive benign and malignant distinction requires the nodular surgical excision in order to evaluate any capsular and/or vascular invasion, extra thyroidal extension, and lymphatic and/or systemic metastases $(12,13)$.

Both the low sensitivity and negative predictive value of FNAC in differentiating benign from malignant oncocytic/Hurthle cell lesions have not been supported by the help of molecular analyses and immunocytochemical markers which have proven to be by far ineffective for this discriminatory role (14).

Several authors have suggested that some specific cyto-morphological and architectural features (e.g. small or large cell dysplasia, syncitia, and crowding and dispersive cellular pattern) can reliably sort out an accurate benign and malignant differentiation even though limited agreement has been found also among experienced cytopathologists $(8,9,14,15,16)$. The lack of agreement concerning both the data and the malignant rate needs to be evaluated on large series in order to reduce the overestimated rate.

We aimed at the analysis of a cyto-histological cohort of oncocytic/Hurthle lesions including $150 \mathrm{OCN}$ and 64 benign lesions with predominant oxyphilic/Hurthle component in order to go over the morphologic features for a correct diagnosis.

\section{Subjects and methods}

From January 2008 through December 2011, a total number of 150 retrospective cases out of 10221 thyroid FNACs were diagnosed as OCN in the Division of Anatomic Pathology and Histology of the Catholic University, 'Agostino Gemelli' Hospital of Rome (Italy), and underwent surgery. In the same period, 64 benign cytological lesions with oncocytic/Hurthle cell component in a Hashimoto thyroiditis (HNN) underwent histology and resulted in 15 HT and 49 hyperplastic oxyphilic nodules in HT. All these 64 benign cases had the histological follow-up for clinical reason and presence of Hurthle cell component. All the thyroid nodules were sampled under sonographic (US) guidance mostly by surgeons and endocrinologists and processed with the liquid-based cytological (LBC) method Thin Prep 2000 (Hologic Co., Marlborough, MA, USA). The entire series included 53 male and 161 female patients with a median age of 42 years (range $20-70$ years). All aspirations (usually two passes for each lesion) were performed with 25-27 G needles; no on-site assessment of the material adequacy was done. The nodules' sizes ranged from 0.4 to $7 \mathrm{~cm}$. All the subcentimeter lesions were discovered during routine US thyroid check-up performed in the Screening Centre for Thyroid Disease of our hospital. All patients had been appropriately informed regarding the use of LBC method for processing the samples and a written informed consent was signed by all of them.

The aspirated material was fixed with the hemolytic and preservative solution Cytolit after rinsing the needle in this solution. The cells were spun at $50 \boldsymbol{g}$ (rotations per minute) then the sediment was transferred in the Preservcyt solution to be processed with the T2000 automated processor according to the manufacturer's suggestions. The resulting slide was fixed in 95\% ethanol and stained with Papanicolaou, while the remaining material was stored in the Preservcyt solution for eventual additional investigations. The lower limit for the adequacy for each sample was established, according to Goellner et al. (17), in six groups of at least ten cells.

The cytological cases were classified according to the Italian Working Group SIAPEC-IAP classification, which shows several overlapping features with both the Bethesda System and the British RCPath Classifications $(18,19,20,21)$. The above-mentioned categories are defined as follows: TIR1, inadequate or hemorrhagic; TIR2, nonneoplastic lesion; TIR3, follicular lesion/suspected follicular neoplasm; TIR4, suspicious for malignancy; and TIR 5, positive for malignant neoplasm. Our cytological series presented the following distribution of diagnoses for the reference period: $6.5 \%$ TIR1 (nondiagnostic), 79\% TIR2 (nonneoplastic), 10.3\% TIR3 (indeterminate), 1.7\% TIR4 (suspicious), and $2.5 \%$ TIR 5 (malignant).

The morphological diagnosis of OCN was achieved in the presence of more than $95 \%$ of oncocytic/Hurthle cells. These cells were defined by abundant granular cytoplasm, enlarged central or eccentric nuclei and prominent nucleoli. The diagnosis of HT was made in the presence of lymphocytes percolating between follicular thyroid cells with single or small groups of oncocytic/Hurthle cells. The benign diagnosis of hyperplastic nodule with oncocytic/Hurthle nodule in HT was made with the presence of some oncocytic/Hurthle cells in a lymphocytic background. All cases, including the histological sections, were reviewed by two expert pathologists (E D Rossi and G Fadda) and those cases whose interpretation was equivocal were submitted to the diagnostic judgment of the other pathologists until a final agreement was achieved. All the morphological parameters described in detail in our following tables were reevaluated in our $150 \mathrm{OCN}$.

Owing to the morphological features of oncocytic/ Hurthle cells, we did not perform any immunocytochemical analyses which would not have added any further information.

\section{Histology}

All surgical specimens were fixed in $10 \%$ buffered formaldehyde, embedded in paraffin and the $5 \mu$-thick microtome sections were stained with hematoxylineosin. A section was done every $0.5 \mathrm{~mm}$ for an extensive 
nodular evaluation and all lesions were entirely analyzed. The diagnosis of OCC was achieved in the presence of either capsular or vascular invasion. The diagnosis of papillary thyroid carcinoma (PTC) and its variants was based on the distinctive nuclear features of the neoplastic cells. The diagnosis of oncocytic/Hurthle papillary carcinoma was defined by the presence of oncocytic/Hurthle cells with the nuclear features of PTC usually arising in a background of HT (2). The fibro adipose tissue surrounding the thyroid gland was included for the lymph nodes research.

\section{Statistical analysis}

Statistical analysis was performed using a commercially available statistical software package (SPSS 10.0) for Windows (Microsoft). Comparison of categorical variables was performed by $\chi^{2}$ test, using the Fisher's exact test when appropriate. A $P$ value $<0.05$ was considered significant.

\section{Results}

One hundred and fifty OCN and 64 benign hyperplastic oncocytic/Hurthle counterparts in HT processed by LBC underwent surgery. Table 1 reported the detailed analysis of the clinical-morphological parameters in both groups. In agreement with the literature, the data highlighted the significant correlation between female gender and OCN $(P=0.0160$, OR 2.244 , 95\% CI $1.173-$ 4.293 ) with also a female predominant evidence in the group of benign oncocytic/Hurthle lesions (64\%). All the other parameters, including age, size, histology, and surgery, did not reach statistically significant results.

The nodular diameter of $2 \mathrm{~cm}$ was chosen as the cutoff point, with $57 / 64$ cases ( $89 \%$ ) smaller than $2 \mathrm{~cm}$ in the benign oncocytic/Hurthle group while $75 / 150(50 \%)$ in the OCN group. We found out that 141 out of $150(94 \%)$ OCNs were histologically benign adenomas with nine

Table 1 Distribution of clinical parameters in the categories of benign oncocytic/Hurthle lesions and oncocytic neoplasms.

\begin{tabular}{lcc}
\hline & $\begin{array}{c}\text { Benign oncocytic/ } \\
\text { Hurthle lesions } \\
(64 \text { cases) }\end{array}$ & $\begin{array}{c}\text { Oncocytic/Hurthle } \\
\text { neoplasms } \\
(150 \text { cases) }\end{array}$ \\
\hline Sex & $23(36 \%)$ & $30(20 \%)$ \\
Male & $41(64 \%)$ & $120(80 \%)$ \\
Women & $42(20-70)$ & $42(20-70)$ \\
Age (years) & $57(89 \%)$ & $75(50 \%)$ \\
Size (cm) & $7(11 \%)$ & $75(50 \%)$ \\
$<2$ & $60(93.7 \%)$ & $41(94 \%)$ \\
$>2$ & $4(6.2 \%)$ & $9(6 \%)$ \\
Histology & 0 & $17(11.3 \%)$ \\
Benign & Malignant & $133(88.6 \%)$ \\
Surgery & $64(100 \%)$ & \\
Lobectomy & & \\
Total thyroidectomy & &
\end{tabular}

Table 2 Distribution of cyto-histological diagnoses in the categories of 64 benign oncocytic/Hurthle lesions and 150 oncocytic/Hurthle cell neoplasms.

\begin{tabular}{lcc}
\hline & $\begin{array}{c}\text { Benign oncocytic/ } \\
\text { Hurthle lesions } \\
\text { (64 cases) }\end{array}$ & $\begin{array}{c}\text { Oncocytic/Hurthle } \\
\text { neoplasms } \\
\text { (150 cases) }\end{array}$ \\
\hline HT & $15(23.4 \%)$ & $10(6.6 \%)$ \\
Goiter & $45(70.3 \%)$ & $20(13.6 \%)$ \\
OCA & 0 & $111(74 \%)$ \\
PTC & $4(6.2 \%)$ & $1^{\mathrm{a}}(0.6 \%)$ \\
OPTC & 0 & $3(2 \%)$ \\
OCC & 0 & $5(3.3 \%)$ \\
\hline
\end{tabular}

HT, Hashimoto thyroiditis; OCA, oncocytic/Hurthle cell adenoma; PTC, papillary thyroid cancer; OPTC, oncocytic/Hurthle variant of PTC; OCC, oncocytic/Hurthle cell carcinoma.

${ }^{\text {aT }}$ This case was histologically diagnosed as macrofollicular variant of papillary carcinoma.

$(6 \%)$ having malignant histology, whereas in the benign counterparts only four out of $64(6.2 \%)$ were malignant, without any statistical correlation between the groups (Table 1).

The surgical treatment revealed a predominant surgical approach with total thyroidectomy in both categories ranging from $88.6 \%$ in the OCNs to $100 \%$ in the benign category (Table 1).

The detailed evaluation of the histological outcome for both groups was pointed out in Table 2. The histological diagnoses for the benign hyperplastic oncocytic/Hurthle lesions in HT resulted in 15 HT, 45 hyperplastic oncocytic/Hurthle nodules, and four PTC in a background of HT (Table 2). The data for the 150 OCN revealed ten HT, 20 goiters with oncocytic/Hurthle features, 111 OCA, one PTC, three oncocytic/Hurthle PTC, and five OCC. For our purposes, we did not include any incidental micro carcinoma.

We correlated the nine OCNs which were histologically malignant with some specific morphological parameters. The data did not act out any correlation with patients' age ranging from 23 to 68 years old or with size ranging from 9 to $50 \mathrm{~mm}$, although we had a mild female predominance in six out of nine $(66.6 \%)$ patients. All the OCCs were diagnosed by their capsular invasion and $60 \%$ (three out of five) by vascular invasions. In the group of PTCs and its oncocytic/ Hurthle variant, only one case presented vascular invasion (Table 3). Independently from their histotypes, all our malignant patients are still alive and without local or/and distant metastases.

In Table 4, we analyzed the distribution of several cytological parameters in the OCN category as previously proposed in other papers. All the cases were reviewed based on the morphological parameters proposed. We supported the evidence that the histological diagnosis of oncocytic/Hurthle malignancy was mainly linked with larger oncocytic/Hurthle cells with more dispersive pattern, nuclear dysplasia, and more prominent nucleoli $(14,15,16)$ (Table 4). 
Table 3 The nine malignant outcomes among the $150 \mathrm{OCN}^{\mathrm{a}}$.

\begin{tabular}{lccllll}
\hline & $\begin{array}{c}\text { Age } \\
\text { (years) }\end{array}$ & Size & Sex & Histology & $\begin{array}{l}\text { Vascular } \\
\text { invasion }\end{array}$ & $\begin{array}{l}\text { Capsular } \\
\text { invasion }\end{array}$ \\
\hline OCN & 23 & 30 & Male & MFV-PTC & No & No \\
OCN & 27 & 50 & Male & OCC & Yes & Yes \\
OCN & 68 & 20 & Female & OCC & Yes & Yes \\
OCN & 63 & 40 & Female & OCC & No & Yes \\
OCN & 55 & 13 & Female & OCC & No & Yes \\
OCN & 68 & 20 & Male & OCC & Yes & Yes \\
OCN & 39 & 10 & Female & OPTC & Yes & No \\
OCN & 43 & 9 & Female & OPTC & No & No \\
OCN & 44 & 45 & Female & OPTC & No & No \\
\hline
\end{tabular}

OCN, oncocytic/Hurthle cell neoplasm; OCC, oncocytic/Hurthle cell cancer; MFV-PTC, macrofollicular variant of papillary thyroid cancer; OPTC, oncocytic/Hurthle variant of PTC.

${ }^{a} A l l$ the patients are still alive and without any local and/or distant metastasis.

\section{Discussion}

The cytological diagnosis of $\mathrm{OCN}$ has been frequently associated with a worse outcome, although this neoplasm is a relatively rare thyroid entity $(9,10)$. The main difficulty is found in grading the oncocytic/ Hurthle atypia, which might discriminate oncocytic adenomas from OCC and which might select the best treatment $(6,7)$. Owing to the wide range of pathologies with oncocytic components, it is justified that a definitive classification can be challenging $(11,18,19,20,21,22)$.

Although the morphological definition of the oncocytic/Hurthle cell (round or ovoid pleomorphic nuclei, prominent central nucleoli, and large granular oxyphilic cytoplasms; Fig. 1) is well established in both cytological and histological fields, the problem mainly lies in a the doubtful cytological collocation in a specific diagnostic category which might lead to a possible misdiagnosis of papillary and medullary carcinomas and its oncocytic variants (Fig. 2).

Several papers have looked into some additional morphological and architectural features that could

Table 4 Distribution of cytological parameters in the category of 150 oncocytic/Hurthle cell neoplasms (OCN) with histological outcome.

\begin{tabular}{|c|c|c|}
\hline & $\begin{array}{l}\text { OCN with benign } \\
\text { histology } \\
\text { (141 cases) }\end{array}$ & $\begin{array}{l}\text { OCN with } \\
\text { malignant } \\
\text { oncocytic/Hurthle } \\
\text { histology } \\
\text { (nine cases) }\end{array}$ \\
\hline Colloid in droplets & Few & Absent \\
\hline Lymphocytic infiltration & Scant/absent & Scant/absent \\
\hline Hypercellularity & Not typical & Frequent \\
\hline $\begin{array}{l}\text { Small oncocytic/Hurthle } \\
\text { cells }\end{array}$ & Predominant & $50 \%$ \\
\hline $\begin{array}{l}\text { Large oncocytic/Hurthle } \\
\text { cells }\end{array}$ & Absent & $50 \%$ \\
\hline Dyscohesive pattern & Absent & Present \\
\hline Nuclear clearing & Rare & Some \\
\hline
\end{tabular}

reliably differentiate benign from malignant oncocytic/ Hurthle lesions, although the OCA largely outnumber carcinomas at histology $(6,9,10,14,19,20,23)$. The more accurate parameters for a diagnosis of carcinoma include the concept of small cell dysplasia, large cell dysplasia, syncitia, crowding and dispersive cellular pattern which result in a difficult reproducibility in everyday practice. Hence, in series described by Nguyen and Gonzales-Campora, the presence of extensive cellularity, large/pleomorphic nuclei, and monomorphic small cells favor a diagnosis of carcinoma, while several other authors have also suggested the evaluation of some further clinical parameters such as gender, size of the lesion, and age $(14,15,16,24,25$, $26,27)$. In this regard, very few papers have specifically underlined the cytological parameters which might be helpful in discriminating between benign and malignant oncocytic neoplasms, whereas clinical parameters to guide the preoperative decision making have been sought by numerous investigators $(9,13,14,22,24$, $25,26,27,28)$.

Our results are evaluated on a large series of $150 \mathrm{OCN}$ on cytology, in contrast with several literature reports characterized by the major limit of a small cohort of patients $(10,24,25,26,27,29,30)$. Contrasting with Tyler, we did not find any correlation with age, size, and risk of malignancy in patients older than 50 as emerged in only one out of five $(25 \%)$ OCC $<2 \mathrm{~cm}$ in size $(14,15$, $16,27)$. Furthermore, our data have been supported by other recent papers, in which the authors have reported similar risk of malignancy for same-sized nodules without any statistical difference $(24,25,26,27)$.

Based on the criteria proposed in Table 4 and revised by more than one pathologist, our cytological retrospective evaluation of the 150 cytological slides of OCN, and mainly of the nine histological malignancies, highlighted a more dispersive cellular pattern of the cells and mild nuclear dysplasia in the oncocytic/ Hurthle malignant outcome. We are in agreement with a paper published in collaboration with the group of Baloch and with the assertions clearly and provokingly 


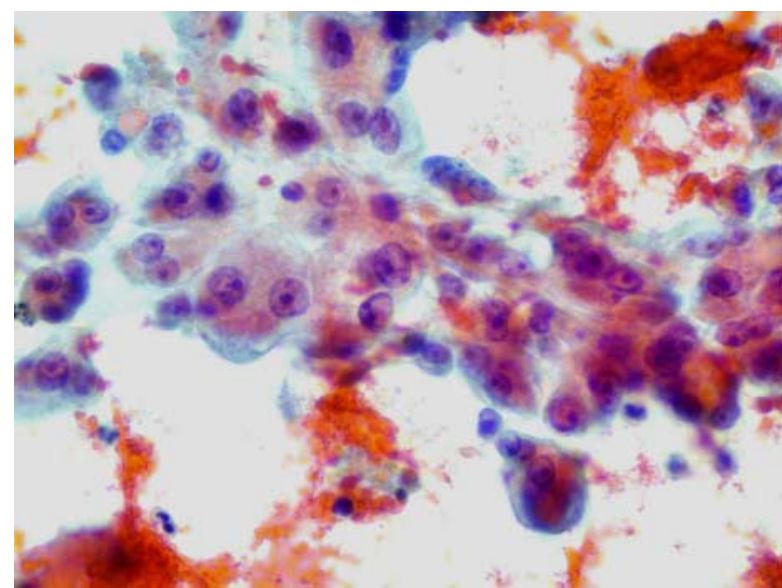

Figure 1 Oncocytic/Hurthle cells showing a moderate nuclear pleomorphism (250 $\times$ Papanicolaou). Full colour version of this figure available via http://dx.doi.org/10.1530/EJE-13-0431.

set out by Renshaw in his paper where some of these features were statistically established more frequently in the malignant outcome with a significant increase in the specificity of FNAC $(14,30)$.

As shown in Table 4, retrospectively we analyzed the distribution of cytological parameters but, probably due to the limited number of our malignant outcome, we did not recognize very specific parameters apart from the well-known represented by i) slightly larger cells and ii) a more dispersive cellular pattern which cannot be definitively associated with a malignant OCC as stated in other series $(9,14)$.

A further problem has been underlined in few recent papers by Roh and by Canberk, where the authors compared the different risk of malignancy in cases of oncocytic proliferation with presence or absence of HT, which is often responsible for the pitfalls due to the reactive nuclear atypia and pleomorphisms $(22,28)$. Additionally, our previous paper on HTs stated that the evidence of the lymphocytic component is a key feature of thyroiditis with a 94\% histologically benign diagnosis, in the same way that Giorgadze et al. expressed their concern in the over-diagnosis of pleomorphisms and grooves in the presence of the lymphocytic component $(14,29)$.

Among the 64 benign cytological counterparts, four false-negative cases were histological PTC probably due to the fact that we attributed the limited nuclear irregularities and nuclear pleomorphisms as a consequence of inflammatory changes in HT. Among the 150 OCNs, histology revealed four PTC as three cases of oncocytic/Hurthle variant of PTC and one macrofollicular variant of PTC, which are both difficult diagnoses. For the latter, the cytological features may sometimes show misdiagnosed nuclear and cytoplasm malignant details as stated by Alaedeen et al. Yang et al. and Fadda et al. $(9,31,32)$. For the former, Renshaw (33) referred to some difficulties in defining the cytological diagnosis of the oncocytic variant of PTC apart from Hurthle cell neoplasms as emerged in his detection of only three oncocytic/Hurthle lesions out of 18 with nuclear features of PTC. A multidisciplinary revision of our cytological slides did not point out any features which were consistent with PTC, although in none of our cases the immunocytochemical panel made up of HBME- 1 and Galectin-3 was applied.

Eventually, we proved our OCN malignant rate was significantly lower in comparison with that of several other cohorts of patients, probably reflecting a different selection bias of OCN and that our global $6 \%$ malignant OCN group is no higher than the rate found in the non-neoplastic group $(9,10,11,14)$. Only two series from Gosain with 5\% and Gonzales $8 \%$ reported a similar malignant rate for the $\operatorname{OCC}(34,35)$. Nonetheless, we agreed that the evidence of multinucleations, mitoses, necrosis, and large irregular nuclei might not rule out a cytological diagnosis of oncocytic malignant lesion.

The evaluation is different when we consider the malignant histotypes for the fact that we did not find any OCCs among the 64 oncocytic/Hurthle lesions, whereas the percentage of OCC in the OCN category was about 3.3\%. Providing a comparative rate between the PTC hystotype in the two categories (including the 64 benign lesions and the $150 \mathrm{OCN}$ ), our data pointed out a higher rate of classical PTC in the category of 64 benign lesions $(6.2$ vs $0.6 \%)$ due to the lower percentage of oncocytic cells in the category of benign lesion with oncocytic features.

The need for morphological and architectural parameters has also been enhanced by the evidence that ancillary techniques such as immunocytochemical panels or mutational analyses cannot reliably and accurately distinguish benign from malignant oncocytic/Hurthle lesions $(23,29,36,37,38,39)$. Nevertheless, recent papers suggest that OCC seems to be

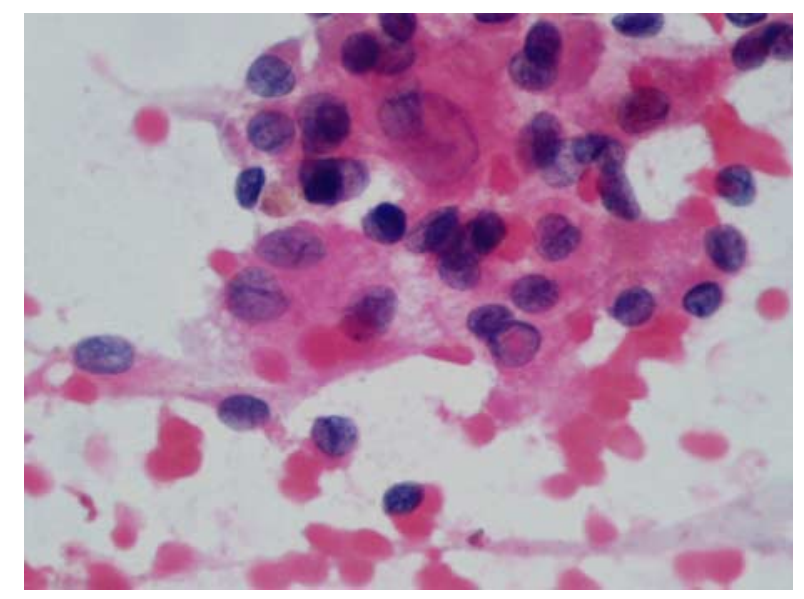

Figure 2 Nuclear clearing and pseudo inclusions are distinctive features of the oncocytic/Hurthle variant of papillary carcinoma (400 $\times$ Papanicolaou). Full colour version of this figure available via http://dx.doi.org/10.1530/EJE-13-0431. 
associated with increased allelic alterations on chromosomal arms $1 \mathrm{q}$ and $2 \mathrm{p}$ and with overexpression of p27(kip1) and cyclin D3 (40, 41).

Furthermore, a very recent paper by Dettmer et al. (39) has highlighted the role of a specific miRNA, the MIR 885, as upregulated in oncocytic/Hurthle cancers even though its value as a diagnostic test needs to be confirmed by additional studies. Concerning the use of immunocytochemistry, in particular Galectin-3, contradictory results were reported in the literature and also in our personal experience ascribed to different technical procedures used to reveal the immunomarker expression in the oncocytic/Hurthle cells which are rich in endogenous biotin $(29,32,38)$.

A conclusive note should be added concerning the application of the LBC method used in our cytological practice which leads to the same result as conventional cytology in terms of feasibility, simplicity, and clear evaluation of the cellular details (1). Even though these low malignant rates could be attributed to the use of the 'alternative LBC method', our previous paper supports the perfect diagnostic concordance between conventional cytology and LBC $(1,29)$.

In conclusion, the 'nightmare' of OCN ought to be regarded similarly as indeterminate proliferations linked to a low malignant rate and handled with less aggressive surgical treatment as also stated in several papers $(13,42,43,44,45)$. Our final suggestion, based on the inter-observer variability on oncocytic/Hurthle cells, is to perform a second FNAC after a period of 6 months if any of the additional morphological features are not present. In case of surgical treatment we advocate a conservative approach of a lobectomy plus isthmectomy with a further surgical reevaluation only for those patients signed out with a final histological diagnosis of malignant neoplasm.

\section{Declaration of interest}

The authors declare that there is no conflict of interest that could be perceived as prejudicing the impartiality of the research reported.

\section{Funding}

This research did not receive any specific grant from any funding agency in the public, commercial or not-for-profit sector.

\section{Acknowledgements}

The authors thank Egidio Stigliano, Elena Visca, and Paola Lanza for their invaluable technical support. The authors thank Mrs Beth Boyle for the extensive English support and revision.

\section{References}

1 Fadda G \& Rossi ED. Liquid based cytology in fine-needle aspiration biopsies of the thyroid gland. Acta Cytologica 201155 389-400. (doi:10.1159/000329029)
2 Baloch ZW \& LiVolsi VA. Follicular-patterned lesions of the thyroid: the bane of the pathologist. American Journal of Clinical Pathology 2002117 143-150. (doi:10.1309/8VL9-ECXY-NVMX-2RQF)

3 LiVolsi VA. Surgical pathology of the thyroid. In Major Problems in Pathology, vol 5. Philadelphia: WB Saunders, 1990.

4 Rosai J, Carcangiu ML \& DeLellis RA. Tumors of the thyroid gland. In Atlas of Tumor Pathology, 3rd series. Fascicle 5, Washington, DC: Armed Forces Institute of Pathology, 1992.

5 Lloyd R.V, Khan A \& Nose' V. Pathology of the thyroid gland. In Endocrine Pathology. Differential Diagnosis and Molecular Advances, pp 153-189. Totowa, NJ: Humana Press, 2004.

6 Montone KT, Baloch ZW \& LiVolsi VA. The thyroid Hurthle (oncocytic) cells and its associated pathologic conditions: a surgical pathology and cytopathology review. Archives of Pathology E Laboratory Medicine 20088 1241-1250.

7 Skoog L \& Tani E. Hurthle cell carcinoma: time for a drastic change? Cancer Cytopathology 200296 259-260.

8 Sippel RD, Elaraj DM, Khanafshar E, Zarnegar R, Kebebew E, Duh QY \& Clark OH. Tumor size predicts malignant potential in Hurthle cell neoplasms of the thyroid. World Journal of Surgery 200832 702-707. (doi:10.1007/s00268-007-9416-5)

9 Alaedeen DI, Khiyami A \& McHenry CR. Fine needle aspiration biopsy specimen with a predominance of Hurthle cells: a dilemma in the management of nodular thyroid disease. Surgery 2005138 650-657. (doi:10.1016/j.surg.2005.06.047)

$10 \mathrm{Wu} \mathrm{H}$, Clouse J \& Ren R. Fine needle aspiration cytology of Hurthle cell carcinoma of the thyroid. Diagnostic Cytopathology 200836 149-154. (doi:10.1002/dc.20750)

11 Faquin WC \& Baloch ZW. Fine needle aspiration of follicular patterned lesions of the thyroid. Diagnosis, management and follow-up according to National Cancer Institute (NCI) recommendations. Diagnostic Cytopathology 201038 731-739. (doi:10. 1002/dc.21292)

12 Sobrinhos-Simoes M, Maximo V, Castro IV, Fonseca E, Soares P, Garcia-Rostan G \& Oliveira MC. Hurthle (oncocytic) cell tumours of thyroid: etiopathogenesis, diagnosis and clinical significance. International Journal of Surgical Pathology 200513 29-35. (doi:10. 1177/106689690501300104)

13 Cannon J. The significance of Hurthle cell in thyroid disease. Oncologist 201116 1380-1387. (doi:10.1634/theoncologist. 2010-0253)

14 Giorgadze T, Rossi ED, Fadda G, Gupta PK, LiVolsi VA \& Baloch Z. Does the fine-needle aspiration diagnosis of "Hurthle-cell neoplasm/follicular neoplasm with oncocytic features" denote increased risk of malignancy? Diagnostic Cytopathology 200431 307-312. (doi:10.1002/dc.20132)

15 Gonzales-Campora R, Herrero-Zapatero A, Lerma E, Sanchez F \& Galera H. Hurthle cell and mitochondrion-rich cell tumors. A clinico-pathologic study. Cancer $1986 \quad \mathbf{5 7} \quad 1154-1163$. (doi:10.1002/1097-0142(19860315)57:6<1154::AID-CNCR 2820570616> 3.0.CO;2-W)

16 Nguyen GK, Ginsberg J, Crockford PM \& Villanueva RR. Hashimoto's thyroiditis: cytodiagnostic accuracy and pitfalls. Diagnostic Cytopathology 199716 531-536. (doi:10.1002/ (SICI) 1097-0339(199706)16:6 < 531::AID-DC12 > 3.0.CO;2-J)

17 Goellener JR. Problems and pitfalls in thyroid cytology. Monographs in Pathology 199739 75-93.

18 Fadda G, Basolo F, Bondi A, Bussolati G, Crescenzi A, Nappi O, Nardi F, Papotti M, Taddei G, Palombini L et al. Cytological classification of thyroid nodules. Proposal of the SIAPEC-IAP Italian consensus working group. Pathologica $2010 \mathbf{1 0 2}$ 405-408.

19 Baloch ZW, LiVolsi VA, Asa SL, Rosai J, Merino MJ, Randolph G, Vielh P, DeMay RM, Sidawy MK \& Frable WJ. Diagnostic terminology and morphologic criteria for cytologic diagnosis of thyroid lesions: a synopsis of the National Cancer Institute fine-needle aspiration state-of-science conference. Diagnostic Cytopathology 200836 425-437. (doi:10.1002/dc.20830)

20 Ali SZ \& Cibas ES. The Bethesda system for reporting thyroid cytopathology. New York, NY: Springer, 2010. 
21 British Thyroid Association. In Guidelines for the Management of Thyroid Cancer, 2nd edn, 2007.

22 Canberk S, Griffin C, Wang H, Montone K, LiVolsi V \& Baloch Z. Oncocytic follicular nodules of the thyroid with or without chronic lymphocytic thyroiditis: an institutional experience. CytoJournal 201310 2. (doi:10.4103/1742-6413.106686)

23 Ganly I, Ricarte FJ, Eng S, Ghossein R, Morris LG, Liang Y, Socci N, Kannan K, Mo Q, Fagin JA et al. Genomic dissection of Hurthle cell carcinoma reveals a unique class of thyroid malignancy. Journal of Clinical Endocrinology and Metabolism 201398 E962-E972. (doi:10.1210/jc.2012-3539)

24 Raparia K, Min SK, Mody DR, Anton R \& Amrikachi M. Clinical outcome for suspicious category in thyroid fine needle aspiration biopsy. Patient's sex and nodule size are possible predictors of malignancy. Archives of Pathology \& Laboratory Medicine 2009133 787-790.

25 Strazisar B, Petric R, Sesek M, Zgajnar J, Hocevar M \& Besic N. Predictive factors of carcinoma in 279 patients with Hurthle cell neoplasm of the thyroid gland. Journal of Surgical Oncology 2010 101 582-586. (doi:10.1002/jso.21526)

26 Kim ES, Nam-Goong IS, Gong G, Hong SJ, Kim WB \& Shong YK. Postoperative findings and risk for malignancy in thyroid nodules with cytological diagnosis of the so-called follicular neoplasms. Korean Journal of Internal Medicine 200318 94-97.

27 Tyler DS, Winchester DJ, Caraway NP, Hickey RC \& Evans DB. Indeterminate fine needle aspiration biopsy of the thyroid: identification of subgroups at high risk for invasive carcinoma. Surgery 1994116 1054-1060.

28 Roh MH, Jo VY, Stelow EB, Faquin WC, Zou KH, Alexander EK, Larsen PR, Marquse E, Benson CB, Frates MC et al. The predictive value of the fine needle aspiration diagnosis suspicious for a follicular neoplasm, Hurthle type in patients with Hashimoto thyroiditis. American Journal of Clinical Pathology 2011135 139145. (doi:10.1309/AJCPORW2WMDUAKGK)

29 Rossi ED, Zannoni GF, Lombardi CP, Vellone VG, Moncelsi S, Papi G, Pontecorvi A \& Fadda G. Morphological and immunocytochemical diagnosis of thyroiditis: comparison between conventional and liquid based cytology. Diagnostic Cytopathology 201240 404-409. (doi:10.1002/dc.21782)

30 Renshaw AA. Hurthle cell carcinoma is a better gold standard than Hurthle cell neoplasm for fine needle aspiration of the thyroid. Cancer Cytopathology 200296 261-266.

31 Yang GC, Schneiner AM \& Sun W. Can abundant colloid exclude oncocytic (Hurthle cell) carcinoma in thyroid fine needle aspiration? Cytohistological correlation of 127 oncocytic (Hurthle cell) lesions. Cytopathology 201324 185-193. (doi:10.1111/j. 1365-2303.2012.00988.x)

32 Fadda G, Rossi ED, Raffaelli M, Pontecorvi A, Sioletic S, Morassi F, Lombardi CP, Zannoni GF \& Rindi G. Follicular thyroid neoplasms can be classified as low and high risk according to HBME-1 and Galectin 3 expression on liquid based fine needle cytology. European Journal of Endocrinology $2011 \mathbf{1 6 5} 447-453$. (doi:10.1530/EJE-11-0181)

33 Renshaw AA. Fine needle aspirations of papillary carcinoma with oncocytic features. An expanded cytologic and histologic profile. Cancer Cytopathology 2011119 247-253. (doi:10.1002/cncy. 20148)
34 Gosain AK \& Clark OH. Hurthle cell neoplasm. Malignant potential. Archives of Surgery 1984119 515-519. (doi:10. 1001/archsurg.1984.01390170015004)

35 Gonzalez JL, Wang HH \& Ducatnab BS. Fine needle aspiration of Hurthle cell lesions. A cytomorphologic approach to diagnosis. American Journal of Clinical Pathology 1993100 231-235.

36 Schmitt F. Molecular cytopathology and flow cytometry: preanalytical procedures matter. Cytopathology 201122 355-357. (doi:10.1111/j.1365-2303.2011.00941.x)

37 Schmitt FC, Longatto-Filho A, Valent A \& Vielh P. Molecular techniques in cytopathology practice. Journal of Clinical Pathology 200861 258-267. (doi:10.1136/jcp.2006.044347)

38 Volante M, Bozzalla-Cassione F, DePompa R, Saggiorato E, Bartolazzi A, Orlandi F \& Papotti M. Galectin-3 and HBME-1 expression in oncocytic cell tumors of the thyroid. Virchows Archiv 2004445 183-188. (doi:10.1007/s00428-004-1074-5)

39 Dettmer M, Vogetseder A, Durso MB, Moch H, Komminoth P, Perren A, Nikiforov Y \& Nikiforova M. MicroRNA expression array identifies novel diagnostic markers for conventional and oncocytic follicular thyroid carcinomas. Journal of Clinical Endocrinology and Metabolism 201398 E1-E7. (doi:10.1210/jc.2012-2694)

40 Evans HL, Vassilopoulou-Sellin R \& Follicular ND. Hurthle cell carcinoma of the thyroid: a comparative study. American Journal of Surgical Pathology $1998 \quad 22$ 1512-1520. (doi:10.1097/ 00000478-199812000-00008)

41 Segev DL, Saji M \& Philips GS. Polymerase chain reaction-based microsatellite polymorphisms analysis of follicular and Hurthle cell neoplasms of the thyroid. Journal of Clinical Endocrinology and Metabolism 199883 2036-2042. (doi:10. 1210/jc.83.6.2036)

42 Elliott DD, Pitman MB, Bloom L \& Faquin WC. Fine needle aspiration biopsy of Hurthle cell lesions of the thyroid gland. A cytomorphologic study of 139 cases with statistical analysis. Cancer Cytopathology $2006 \mathbf{1 0 8} 102-109$.

43 Alexander EK, Kennedy GC, Baloch ZW, Cibas ES, Chudova D, Duggans J, Friedman L, Kloos RT, LiVolsi VA, Mandel SJ et al. Preoperative diagnosis of benign thyroid nodules with indeterminate cytology. New England Journal of Medicine $2012 \mathbf{3 6 7}$ 705-715. (doi:10.1056/NEJMoa1203208)

$44 \mathrm{Pu}$ RT, Yang J, Wasserman PG, Bhuiya T, Griffith KA \& Michael CW. Does Hurthle cell lesion/neoplasm predict malignancy more than follicular lesion/neoplasm on thyroid fine-needle aspiration? Diagnostic Cytopathology 200634 330-334. (doi:10. 1002/dc.20440)

45 Turani S, Pirhan Y, Caglar KO \& Cetin A. Predictors of malignancy in patients with a thyroid nodule that contains Hurthle cells. Otolaryngology-Head and Neck Surgery $2011 \mathbf{1 4 4}$ 514-517. (doi:10.1177/0194599810394052)

Received 21 May 2013

Revised version received 8 August 2013

Accepted 28 August 2013 